\title{
Unmet Need, Intention to Use Contraceptives And Unwanted Pregnancy in Rural Bangladesh
}

\section{By Rebecca \\ Callahan and Stan Becker}

Rebecca L. Callahan is scientist at FHI 360, Durham, NC, USA. Stan Becker is professor, Department of Population, Family and Reproductive Health, Johns

Hopkins Bloomberg School of Public Health, Baltimore, MD, USA.

\begin{abstract}
CONTEXT: Unmet need for contraception has become a central concept in the family planning field and one of the most important indicators for program planning and evaluation. The measure has faced criticism, however, for not taking into account women's stated intention to use contraceptives.
\end{abstract}

METHODS: Using longitudinal data on more than 2,500 rural Bangladeshi women in 128 villages, this study links women's contraceptive adoption and experience of unwanted pregnancy between 2006 and 2009 to their unmet need status and their stated intention to use contraceptives in 2006.

RESULTS: Intention to use a method was predictive of subsequent use for both women with and without an unmet need. Three-quarters of the unintended pregnancies reported between 2006 and 2009 occurred among women without an unmet need in 2006. In addition, nearly half of women without an unmet need who were pregnant or postpartum in 2006 had experienced an unwanted pregnancy, compared with $30 \%$ of all women classified as having an unmet need.

CONCLUSION: To adequately meet population family planning needs, programs must look beyond unmet need and focus on the total demand for acceptable and effective methods.

International Perspectives on Sexual and Reproductive Health, 2014, 40(1):4-10, doi: 10.1363/4000414

The measure of unmet need for contraception represents a core concept in the field of family planning and is one of the most important indicators for family planning policy, programs and research. A general concept of unmet need has existed almost as long as the international family planning movement has been in existence, beginning with researchers in the 1960s describing the discrepancy between women's stated desire to limit childbearing and their actual use of contraceptives. ${ }^{1,2}$ Measurement of this gap between knowledge, attitude and practice-the "KAP-gap"-was included in national family planning studies in developing countries from the 1960s through the 1980s. Charles Westoff and colleagues further refined the concept to take into consideration pregnancy, postpartum amenorrhea, fecundity and women's desire to space births. ${ }^{3-6}$ Recently, Bradley et al. revised the unmet need measure to reduce its complexity and allow for more consistent application across time and countries. ${ }^{7}$ The core of the concept, however, remains based on an algorithm that assigns unmet need to women who are married or in union and are fecund, but

\footnotetext{
*More detailed descriptions of the history of the concept of unmet need have been published elsewhere (sources: Sedgh $\mathrm{G}$ et al., Women with an unmet need for contraception in developing countries and their reasons for not using a method, Occasional Report, New York: Guttmacher Institute, 2007, No. 37; and Casterline JB and Sinding SW, Unmet need for family planning in developing countries and implications for population policy, Population and Development Review, 2000, 26(4):691-723). Bradley et al. provide a detailed description of measurement issues related to unmet need and recent changes to the DHS definition of the measure (source: Bradley SEK et al., Revising unmet need for family planning, DHS Analytical Studies, Calverton, MD, USA: ICF International, 2012, No. 25).
}

do not want a child in the next two years and are not using any method of contraception. Pregnant and amenorrheic women are considered to have an unmet need if they say that their current or last pregnancy was unintended. ${ }^{* 6}$

Over the last three decades, recommendations have been made to improve the concept of unmet need, including accounting for the need for more effective family planning among women using traditional methods, ${ }^{8,9}$ pregnant and postpartum women's future fertility intentions, ${ }^{10}$ husbands' preferences and the unmet need of the couple,$^{11,12}$ and the unique contraceptive needs of unmarried women. ${ }^{8,13}$ Researchers have also argued that to more effectively gauge actual contraceptive demand, the measure of unmet need should account for women's intention to use contraceptives, ${ }^{10,14}$ and that a sizeable proportion of women classified as having an unmet need would not use contraceptives even if they were available. Therefore, using unmet need as the measure of contraceptive demand may be misleading. ${ }^{15,16}$

Due to a lack of appropriate longitudinal data, few studies have assessed the value of the unmet need measure for predicting future contraceptive use or compared outcomes among women classified as having an unmet need according to whether or not the women intend to use a method. Analyses of cross-sectional Demographic and Health Survey (DHS) data have shown that $26-83 \%$ of women with an unmet need across 48 countries report intending to use a method. ${ }^{15}$ DHS data also show that many women who intend to use are not classified as having an unmet need, 
usually because they report their current pregnancy as intended or are amenorrheic and report their last birth as wanted. However, many of these women do not want to become pregnant again soon, and many say they intend to use contraceptives. According to Ross and Winfrey, $40 \%$ of postpartum women across 27 countries said they intended to use a method within the next year. ${ }^{10}$ Using data from a rare DHS panel survey in Morocco, Curtis and Westoff found that $40 \%$ of women classified as having an unmet need said they did not intend to practice contraception in the future; however, among these women, 38\% went on to adopt a method within the next three years. ${ }^{17,18}$

Data from a longitudinal study in rural Bangladesh with interviews in 2006 and 2009 provide another opportunity to examine the relationships between unmet need, intention to use contraceptives and unwanted pregnancy over time. These unique data include information on contraceptive use intentions, method adoption and a pregnancy history for more than 3,600 women over the three-year period. The specific aims of the present analysis are: to examine how unmet need changed in the sample population between 2006 and 2009, to explore the relationship between women's intention to use contraceptives and subsequent method use among those with and without an unmet need for contraception, and to determine whether women with an unmet need for contraception were more likely to experience an unwanted pregnancy over the study period than women without an unmet need.

On the basis of prior research assessing predictors of unmet need in Bangladesh, we hypothesized that women who had never attended school or who had not used a method in the past would be more likely than those who had attended school or used a method to have an unmet need in both 2006 and 2009. ${ }^{19}$ Since previous longitudinal studies have found that stated intention to practice contraception is predictive of subsequent contraceptive adoption, we also hypothesized that women who had had an unmet need for contraception at the start of the study would be more likely to begin use of a method between surveys if they had intended to use at baseline. ${ }^{14,18}$ However, we predicted that women with an unmet need who had not intended to use a method were more likely to experience an unwanted pregnancy than those who had intended to use.

\section{METHODS}

The data used in this analysis come from the Bangladesh Microcredit and Health Study (BMHS), an experimental study designed to measure the relative effects of microcredit and basic health service interventions-introduced both separately and jointly-on the use of health services, economic well-being and women's empowerment. The study was conducted in 128 rural villages in three divisions of Bangladesh (Chittagong, Dhaka and Rajshahi) over a period of three years. Villages were eligible for the intervention if fewer than $50 \%$ of households participated in microcredit activities and if the village's health programs were exclusively government-run. * The study consisted of a 2006 baseline household survey and a 2009 follow-up survey, which used a largely identical community, household, women's and husband's questionnaires. Our analysis is based on data from the women's questionnaires.

\section{Sample}

On the basis of a census conducted in the study villages prior to the baseline survey, households were divided into three wealth categories consistent with Grameen Bank standards: not eligible for microcredit (household owns more than half an acre of land), eligible and currently involved in microcredit activities, and eligible but not currently involved in microcredit activities. For the survey, a proportional random sample was taken from these three strata among all households in each village. In each village, the sample consisted of four women who were ineligible for microcredit, 12 who were eligible and already in a program, and 15 who were eligible but not in a program.

The household response rate for the baseline survey was $91 \%$, and the response rate among women eligible for the BMHS was $99 \%$. Of the 3,933 women who were interviewed at baseline, 3,687 (93\%) completed the follow-up survey. Women who did not complete the follow-up survey were similar to women completing both survey rounds in terms of household wealth, school attendance and experience with contraception. However, the small number who did not complete the second survey were significantly younger and of lower parity than those completing both surveys. A description of women lost to follow-up ${ }^{20}$ and additional details of the experimental study and study design are reported elsewhere. ${ }^{21}$ Women were eligible for the present analysis if they completed both BMHS survey rounds and were married and between the ages of 13-49 at baseline; the final sample totaled 3,024 women.

\section{Measures}

The women's questionnaire collected relevant socioeconomic data, information on microcredit participation, birth history information and details about maternal and child health care, including contraceptive use. Much of the women's questionnaire was modeled after the DHS, including the use of a calendar to document contraceptive use month by month. Birth histories and information on future pregnancy intentions were solicited from currently married women younger than 50 .

In this study, a woman was defined as having an unmet need for limiting births under the following conditions: if she was married, younger than 50 and not using a method; and if she had reported that she was fecund and did not

*The study was conducted in cooperation with the Grameen Health Program, which has established health centers in selected small towns and villages in rural Bangladesh. Villages considered for this study were located outside the catchment areas of these health centers and thus were considered remote. Of the 31 Grameen health centers located in the Chittagong, Dhaka and Rajshahi divisions, the 16 centers with the lowest reported coverage by microcredit activities were first selected. For each of the 16 centers, two sets of four villages were selected in opposite directions from the Grameen health center. 
TABLE 1. Percentage distribution of married women aged 13-49 by self-reported contraceptive use status in 2009, according to status in 2006, Bangladesh

Contraceptive use

status, 2006

\begin{tabular}{lr|lllll} 
& 2006 & $\begin{array}{l}\text { Unmet need } \\
\text { for limiting }\end{array}$ & $\begin{array}{l}\text { Using a } \\
\text { method }\end{array}$ & $\begin{array}{l}\text { Other* } \\
\text { or }\end{array}$ & $\begin{array}{l}\text { Aged }>49 \\
\text { or no longer } \\
\text { married }\end{array}$ & Total \\
\hline $\begin{array}{l}\text { Unmet need } \\
\quad \text { for limiting }\end{array}$ & 388 & 26.0 & 51.8 & 13.9 & 8.3 & 100.0 \\
Using a method & 1,921 & 10.7 & 74.0 & 11.0 & 4.3 & 100.0 \\
Other* & 715 & 15.0 & 42.7 & 34.5 & 7.8 & 100.0 \\
Total & 3,024 & 13.6 & 63.8 & 17.0 & 5.7 & 100.0 \\
\hline
\end{tabular}

*Includes women who reported not using a method because they want to become pregnant, reported being infecund, were pregnant and said their last pregnancy was intended, or were postpartum amenor-

rheic and said their last birth was planned. want any more children, that she was pregnant and did not want her current pregnancy, or that she was no more than seven months postpartum and her most recent birth had been unplanned. Because the BMHS questionnaires asked women only if they wanted more children and not when they would like another pregnancy, we could not calculate unmet need for birthspacing. The BMHS also did not collect information about the duration of amenorrhea and sexual abstinence after births, so we could not directly measure postpartum insusceptibility. For the calculation of unmet need presented here, we assumed that all women who were seven months postpartum or less were amenorrheic or abstaining from sex, since this is the median length of postpartum insusceptibility reported in the 2007 Bangladesh DHS.*22

Intention to use a method was measured in the BMHS by asking pregnant and nonpregnant married women younger than 50 who were not currently using contraceptives, "Do you think you will use a method to delay or avoid pregnancy at any time in the future?" Women who responded

\footnotetext{
*Postpartum insusceptibility refers to the state, following a birth, in which mothers are either still amenorrheic or still abstaining, or both. In the 2007 Bangladesh DHS, the median duration of postpartum insusceptibility was seven months; however, it was longer for women who were rural or poor and for those with no education. Given that our sample was drawn from a rural area, we calculated unmet need using the sevenmonth cutoff and again using a 10-month cutoff. The difference in results was minimal.

tThe household asset index was constructed from several indicators, including having electricity or a wardrobe, table, chair, clock, bed, radio or television; having a motorcycle, sewing machine or telephone; having brick, cement or tin walls; having a modern toilet or pit latrine; and the ratio of the number of people in the household to the number of rooms in the house. Principal components analysis was used to combine the asset indicators and household density figure into an asset index that was assigned to each respondent. ${ }^{21}$

fln the baseline survey, women were asked who in their family had a say and who had the final say on decisions related to buying costly furniture such as a cot or showcase; buying or selling cows or goats; spending family savings; taking out a loan; getting treatment when children were sick; visiting a doctor when the respondent was sick; the respondent's being able to work for money outside the home; the respondent's visiting her father's home; having another child or stopping childbearing; and using family planning. For each item, the woman received a score of 0 if she reported that she did not participate in the decision, 1 if she reported that she contributed to the decision and 2 if she reported herself as the most important or second most important person in deciding The scores for each item were then summed to give the overall decisionmaking score (source: Mahmud S, Shah NM and Becker S, Measurement of women's empowerment in rural Bangladesh, World Development, 2012,40(3):610-619).
}

"yes" were then asked what method they planned to use. The contraceptive calendar, completed as part of the followup women's questionnaire, collected monthly information on all pregnancies, births, terminations and episodes of contraceptive use during the period between the two surveys. A woman was considered to have had an unwanted pregnancy if she reported at baseline that she did not want any more children but reported a pregnancy (regardless of outcome) during the intersurvey period. Other covariates of interest include ever having attended school, ever having used contraceptives, household wealth (measured by an asset index), ${ }^{\dagger}$ women's household decision-making power, ${ }^{\dagger}$ and experience of child death or stillbirth. All data on covariate measures come from the baseline survey.

We constructed bivariate and multivariate logistic regression models to assess the predictors of having an unmet need for contraception for limiting births in both 2006 and 2009. Notably, we have data only from these two time points, so we are not able to assess whether women moved in and out of having unmet need during the threeyear study period.

\section{RESULTS}

\section{Changes in Contraceptive Use and Unmet Need Status}

We first estimated unmet need for limiting births in 2006 and 2009, respectively, among women who participated in both rounds of the study. At baseline, 13\% of the 3,024 women had an unmet need: They either wanted to limit births but were not using a method of contraception, were pregnant and reported that their current pregnancy was unwanted, or were postpartum and reported that their last birth had been unplanned. By 2009, this proportion had increased to $15 \%$. Overall unmet need for limiting between the two time points rose mainly because a larger proportion of women in 2009 than in 2006 reported not using a method although they were not pregnant or amenorrheic and said they did not want more children.

Many women moved between categories of unmet need and contraceptive use between 2006 and 2009. Of the 388 women classified as having an unmet need for limiting births in 2006, more than half had begun using a method by 2009 , while $26 \%$ continued to have an unmet need

\section{TABLE 2. Among married women aged 13-49, adjusted odds ratios from logistic regression analysis identifying associations between selected characteristics and having had an unmet need in both 2006 and 2009, Bangladesh $(N=2,853)$}

Characteristic (value in 2006)

Odds ratio $(95 \% \mathrm{Cl})$

Age (yrs.)

$1.04(1.01-1.08)^{*}$

Parity

$1.16(1.04-1.29)$

Household asset indext

$1.04(0.92-1.17)$

Ever attended school

$1.31(0.71-1.80)$

Ever used a contraceptive methodł

Decision-making score§

Ever experienced stillbirth or child death

Goodness-of-fit test (prob $>\chi^{2}$ )

$0.98(0.91-1.06)$

$1.09(0.66-1.79)$

$2807.0(0.68)$

${ }^{*} p<0.05 .{ }^{* * *} p<0.001$. †Asset index ranges from -4.49 to 3.81 . \#Reference category "no." §Decision-making scores range from 0 to 20. Note: Adjusted for sample design. 
(Table 1). Among women who were using a method in 2006, nearly three-fourths also reported use in 2009; however, $11 \%$ of those who were using a method at baseline were no longer using in 2009 although they had reported in the earlier survey that they did not want any more children. (The true proportion of women who discontinued contraceptive use over the three years is actually higher than $11 \%$ because some women discontinued use during the period and then began again before the 2009 survey.) Another $11 \%$ of those who were practicing contraception in 2006 discontinued use because they wanted to become pregnant or because they were no longer fecund.

A logistic regression analysis indicates that the odds of having an unmet need for limiting births in both 2006 and 2009 increased with age (odds ratio, 1.04) and parity (1.2; Table 2). Meanwhile, women who had ever used a method had significantly decreased odds of having an unmet need at both time points, compared with those who had never used a method (0.3). Relative household wealth, schooling, decision-making power, and having experienced a child death or stillbirth were not associated with having had unmet need at both surveys in the multivariate analysis.

\section{Intention to Use Contraceptives and Subsequent Use}

Overall contraceptive prevalence was high in the sampled population at the time of the surveys. Among married women aged 13-49, 64\% reported current method use in 2006, and 67\% did so in 2009 (not shown). Of the 1,103 women not using a method in 2006, 65\% reported that they intended to use a method at some point in the future.

Overall, most women who were not using a method at the 2006 survey-both those with and those without an unmet need for limiting births-were using a method in 2009 (69\% and 58\%, respectively; Table 3). The proportion of women who reported using a method in 2009 was higher among those who had previously reported intending to use a method than among those had reported no intention to do so. This was true among both women who had had an unmet need in 2006 (85\% vs. 40\%; unadjusted odds ratio 8.3) and women who had not had an unmet need (74\% vs. $28 \%$; unadjusted odds ratio, 7.2 ).

The majority of women who went on to adopt a method chose either oral or injectable contraceptives, whether they had had (63\%) or had not had (67\%) an unmet need for limiting births in 2006 (Table 4). Although all the women with an unmet need said that they did not want any more children, only $6 \%$ adopted a long-acting or permanent method.

In 2006, 2,064 women said they wanted no more children and thus were considered to have a demand for contraception for limiting births. Of this group, nearly threequarters were using a method of contraception, and most were using a modern method (63\%; Figure 1, page 8). The standard definition of unmet need accounts for fewer than two-thirds of the remaining women wishing to limit births: Eighteen percent of women not wanting another birth were not using a method and would thus have been

\begin{tabular}{|c|c|c|c|c|}
\hline \multirow[t]{2}{*}{ Intend to use contraceptives } & \multicolumn{2}{|c|}{ Unmet need in 2006} & \multicolumn{2}{|c|}{$\begin{array}{l}\text { No unmet need } \\
\text { in } 2006\end{array}$} \\
\hline & No. & $\begin{array}{l}\% \text { using a } \\
\text { method in } \\
2009\end{array}$ & No. & $\begin{array}{l}\text { \% using a } \\
\text { method in } \\
2009\end{array}$ \\
\hline All & 388 & 68.8 & 715 & 57.5 \\
\hline Yes & 252 & 84.5 & 464 & 73.5 \\
\hline No & 136 & 39.7 & 251 & 27.9 \\
\hline \multicolumn{5}{|l|}{ Odds of method use in } \\
\hline 2009 , by intention status & & $8.29 *$ & & $7.17^{*}$ \\
\hline
\end{tabular}

considered to have an unmet need. An additional 10\% of women wanting no more births did not fall under the standard definition of unmet need because they were pregnant or postpartum at the time of the survey and reported that their last pregnancy was intended. A small proportion of both women with and without a defined unmet need (7\%) said they did not intend to use contraceptives even though they expressed a desire for no more children.

\section{Unwanted Pregnancy}

Between 2006 and 2009, 32\% of 2,853 women who were aged 13 to 49 and married at the time of both surveys became pregnant at least once (not shown), and these pregnancies were fairly evenly split between women with and without an unmet need for contraception to limit births in 2006 (30\% and 33\%, respectively). All of the pregnancies among women having an unmet need are considered unwanted. However, $40 \%$ of the pregnancies among women without an unmet need occurred among those who had said they wanted no more children, indicating that these women changed their childbearing intentions, stopped method use or experienced a contraceptive failure.

Forty-seven percent of the 923 pregnancies that occurred during the intersurvey period among women who were married and aged 13-49 were unwanted-i.e., they were conceived by women who had reported in 2006 that they wanted no more children. Three-quarters of the unwanted pregnancies occurred among women who were not classified as having an unmet need in 2006: Half of unwanted pregnancies occurred among women who were using contraception at baseline, and 24\% occurred among those who were pregnant or postpartum at baseline and

\begin{tabular}{|c|c|c|c|c|c|c|c|}
\hline \multirow{2}{*}{$\begin{array}{l}\text { Unmet need } \\
\text { status, } 2006\end{array}$} & \multirow[t]{2}{*}{ No. } & \multicolumn{6}{|c|}{ Method use, 2006-2009 } \\
\hline & & $\begin{array}{l}\text { Oral } \\
\text { contraceptives }\end{array}$ & Injectable & LAPM* & Condom & Traditional & Total \\
\hline Unmet need & 267 & 36 & 27 & 6 & 3 & 28 & 100 \\
\hline No unmet need & 411 & 38 & 29 & 7 & 4 & 22 & 100 \\
\hline
\end{tabular}


FIGURE 1. Total demand for limiting births in 2006 among fecund, married women aged 13-49, by unmet need and intention to use contraceptives in $2006(n=2,064)$

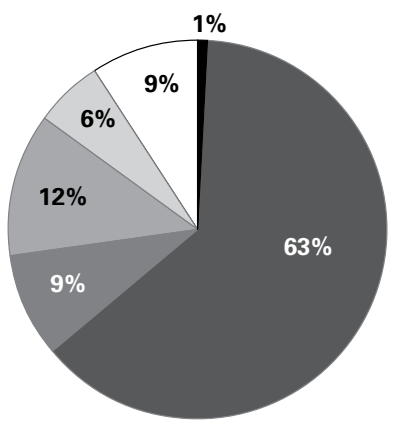

Using a modern method

Using a traditional method

Unmet need, intending to use

Unmet need, not intending to use

No unmet need, intending to use

No unmet need, not intending to use

said their last pregnancy was intended.

Of the 470 women who were pregnant or postpartum at the time of the baseline survey, $31 \%$ went on to have an unwanted pregnancy during the study, a rate roughly equal to that of the larger study population. Among those who had an unwanted pregnancy in 2006-2009, only 23\% would have been considered to have an unmet need for contraception for limiting births on the basis of the reported planning status of their last birth or pregnancy. The vast majority (94\%) of the pregnant and postpartum women who experienced an unwanted pregnancy had said that they intended to use contraceptives.

\section{DISCUSSION}

Family planning researchers, policymakers and program administrators commonly use the indicator of unmet need as a measure of the potential unsatisfied demand for contraception and to judge the success of family planning programs. Although repeat cross-sectional surveys such as the DHS provide estimates of the aggregate levels and changes in unmet need among women over time, they do not provide insight into whether and in what proportions women move in and out of the state of unmet need. ${ }^{17}$ Because unmet need is not something reported by survey respondents themselves and is instead derived from women's reports of desire for children and of contraceptive use, it may not accurately reflect women's (or men's) perception of their need. In addition, the measure can vary significantly depending on how it is defined.

The longitudinal data presented here indicate that in this sample of rural Bangladeshi women, nearly threequarters of those identified as having an unmet need for limiting births in 2006 were no longer in need three years later, according to the prevailing definition of unmet need. While a small proportion of these women were no longer in need in 2009 because of demographic changes, i.e., because they were older than 49 or were no longer married, the majority had moved out of unmet need status because they had begun to use a method. While this finding is encouraging, it is tempered by the fact that overall unmet need for limiting births in the sample increased between the two surveys. The increase in unmet need is primarily due to an increase in the proportion of women who were not pregnant or postpartum but who indicated that they wanted no more children and were not using a method in 2009. This finding is not unexpected, given that women in the sample had aged three years by 2009 , and some had reached their desired family size.

Women who were classified as having an unmet need in both 2006 and 2009 were older and of higher parity than women who did not have an unmet need at either time or who had moved in or out of unmet need status during the study period. Though we had hypothesized that women with consistent unmet need would have had less schooling than other women, no such difference was found in our sample. This could be due to the overall low levels of schooling in this population. Women who had used a method in the past had greatly reduced odds of having had unmet need at both points in time.

The measure of unmet need has been criticized for not taking into account women's stated intention to use contraceptives. ${ }^{10}$ Our results strongly support the assumption that women who say they intend to use a method will go on to use one, whether or not they have an unmet need for contraception. Not surprisingly, the proportion of women who went on to adopt a method in the next three years was greater among those who had said in 2006 that they intended to use a method and had an unmet need than it was among women who had intended to use a method but who had not had an unmet need. However, among women with an unmet need in 2006 and no intention to practice contraception, two-fifths went on to adopt a method, reflecting the fact that many women's intentions change over time. And while we had hypothesized that women with an unmet need who did not intend to use a method would be at heightened risk for unwanted pregnancy, we did not find evidence for this. The vast majority of women who experienced an unwanted pregnancy-both those who were classified as having an unmet need and those who were not-had reported in 2006 that they intended to use a method; however, they did not fulfill their intentions before they became pregnant.

In many contexts, including rural Bangladesh, as the present analysis shows, some proportion of women classified as having an unmet need report that they intend to use a method in the future. ${ }^{16,18}$ At the same time, many women with an unmet need do not intend to use a method, and others who say they intend to practice contraception do not fall into the unmet need category. In our analysis, the groups at risk of miscategorization were those who wanted 
no more children but who were not considered in need either because they were pregnant in 2006 and said that their pregnancy was intended or because they were postpartum and their last birth was planned. Programs that place primary focus on reaching women defined as having an unmet need for contraception risk overlooking these likely motivated groups of potential users.

Prior analyses of DHS data have shown that variation in how unmet need is defined among pregnant and postpartum women can make a sizable difference in overall country-level estimates of unmet need. Ross and Winfrey demonstrated in their analysis of DHS data from 27 countries in the mid-1990s that defining unmet need among women within one year postpartum according to future childbearing preferences, rather than the planning status of their last birth, results in an overall unmet need estimate of $65 \%$ among this group (range, $28 \%$ in Brazil to $88 \%$ in Côte d'Ivoire). ${ }^{10}$ In contrast, global unmet need estimates calculated from 55 surveys conducted around the same time period for all married women using the traditional definition for postpartum women are considerably lower, ranging from $6 \%$ in Colombia to $40 \%$ in Haiti. ${ }^{13}$ Ross and Winfrey argue that because the vast majority of postpartum women do not want another birth soon-in their study, only about $5 \%$ of postpartum women across countries wanted another birth within two years-and because many of these women fail to begin use of a method soon after birth, this group is at heightened risk for unintended pregnancy. Our analysis supports this assertion. Of the 434 unwanted pregnancies reported in our sample between 2006 and 2009, more than one-third occurred among women who were either pregnant or postpartum in 2006, the vast majority of whom were not defined as having an unmet need for contraception.

Unwanted pregnancy was also common among women who were not pregnant or postpartum in 2006 and said they were currently using a method. Half of all unwanted pregnancies occurred in this group. While it is not possible to determine how many of these women's childbearing intentions changed over the three-year period, many of the reported pregnancies were almost certainly the result of contraceptive discontinuation or method failure.

\section{Limitations}

The findings presented here come from data collected for another purpose, and our analyses are therefore limited by the type of data available. Most notably, women were asked in 2006 only whether they wanted to have another child and not when, so we are unable to assess unmet need related to birthspacing in this sample. Undoubtedly, the inclusion of women wanting to delay their next birth who were not using a method would have resulted in a higher estimate of unmet need. Data from the most recent Bangladesh DHS indicate that the total unmet need in the country stands at $12 \%$, and one-third of this need is among women who would like to delay their next birth. ${ }^{23}$

A second limitation is the loss to follow-up of about $7 \%$ of women who completed the baseline survey. These women were younger and had fewer children than those who completed both surveys. While we do not think that the loss of these women introduces any important bias into the analysis, our estimates of unmet need might have been slightly different with their inclusion.

Finally, we used unweighted data from a stratified sample that oversampled poor women; we cannot generalize these findings either to the villages from which the data were collected or to rural Bangladesh. However, we think that this analysis is useful for describing the relationships between unmet need, intention to use contraceptives and subsequent unintended pregnancy, and we believe that the results are relevant for other contexts.

\section{Conclusion}

In summary, we believe our results highlight three important issues for the family planning field. First, the measure of unmet need for family planning has predominantly been used to track aggregate changes in contraceptive demand and not as an individual-level indicator of family planning need. However, the present analysis shows that the measure does apply at the individual level, specifically to identify the women most likely to adopt a method, i.e., those defined as having an unmet need who also say they intend to use contraceptives. It is the task of family planning programs to make available a wide range of methods, including long-acting and permanent methods, so that women and couples can adopt a method that will meet their needs. Second, in the context of this study-and likely in other contexts-the measure of unmet need is not very effective in identifying the contraceptive needs of pregnant and postpartum women. Rather than relying on the reported planning status of these women's last birth or current pregnancy, the unmet need classification would be better if based on the future childbearing preferences of pregnant and postpartum women. Finally, overreliance on the measure of unmet need for measuring contraceptive demand and reducing unwanted pregnancy among nonusers may result in missed opportunities for meeting the needs of existing users-including those using less effective traditional methods-who may be at risk for contraceptive failure or discontinuation. Family planning policymakers and program administrators must focus on the total demand for contraception, ensuring that those with both met and unmet need have access to the most acceptable, appropriate and effective methods of contraception.

\section{REFERENCES}

1. Mauldin WP, Fertility studies: knowledge, attitude, and practice, Studies in Family Planning, 1965, 1(7):1-10.

2. Bongaarts J, The KAP-gap and the unmet need for contraception, Population and Development Review, 1991, 17(2):293-313.

3. Westoff CF, The unmet need for birth control in five Asian countries, Family Planning Perspectives, 1978, 10(3):173-181.

4. Westoff CF and Pebley AR, Alternative measures of unmet need for family planning in developing countries, International Family Planning Perspectives, 1981, 7(4):126-136. 
5. Westoff $\mathrm{CF}$, The potential demand for family planning: a new measure of unmet need and estimates for five Latin American countries, International Family Planning Perspectives, 1988, 14(2):45-53.

6. Westoff CF and Bankole A, The potential demographic significance of unmet need, International Family Planning Perspectives, 1996, 22(1):16-20.

7. Bradley SEK et al., Revising unmet need for family planning, DHS Analytical Studies, Calverton, MD, USA: ICF International, 2012, No. 25 .

8. Dixon-Mueller R and Germain A, Stalking the elusive "unmet need" for family planning, Studies in Family Planning, 1992, 23(5):330-335.

9. Perez AE and Palmore JA, Reevaluating the unmet need for family planning in the Philippines, Asia-Pacific Population Research Reports, Honolulu, HI, USA: East-West Center, 1997, No. 10.

10. Ross JA and Winfrey WL, Contraceptive use, intention to use and unmet need during the extended postpartum period, International Family Planning Perspectives, 2001, 27(1):20-27.

11. Becker S, Measuring unmet need: wives, husbands or couples? International Family Planning Perspectives, 1999, 25(4):172-180.

12. Bankole A and Ezeh AC, Unmet need for couples: an analytical framework and evaluation with DHS data, Population Research and Policy Review, 1999, 18(6):579-605

13. Westoff CF, Unmet need at the end of the century, DHS Comparative Reports, Calverton, MD, USA: ORC Macro, 2001, No.1.

14. Roy TK et al., Can women's childbearing and contraceptive intentions predict contraceptive demand? Findings from a longitudinal study in Central India, International Family Planning Perspectives, 2003 29(1):25-31

15. Ross JA and Heaton L, Intended contraceptive use among women without an unmet need, International Family Planning Perspectives, 1997, 23(4):148-154.

16. Jain A, Should eliminating unmet need for contraception continue to be a program priority? International Family Planning Perspectives, 1999, 25(Suppl.):S39-S43 \& S49.

17. Westoff CF and Bankole A, The time dynamics of unmet need an example from Morocco, International Family Planning Perspectives, 1998, 24(1):12-14

18. Curtis SL and Westoff CF, Intention to use contraceptives and subsequent contraceptive behavior in Morocco, Studies in Family Planning, 1996, 27(5):239-250.

19. Barkat-e-Khuda, Roy NC and Rahman DM, Unmet contraceptive need in Bangladesh: evidence from the 1993/94 and 1996/97 Demographic and Health Surveys, Asia-Pacific Population Journal, 1999, 14(2):37-50.

20. Callahan RL and Becker S, The reliability of calendar data for reporting contraceptive use: evidence from rural Bangladesh, Studies in Family Planning, 2012, 43(3):213-222.

21. Amin R, Shah NM and Becker S, Socioeconomic factors differentiating maternal and child health-seeking behavior in rural Bangladesh: a cross-sectional analysis, International Journal for Equity in Health, 2010, 9(9):1-11.

22. National Institute of Population Research and Training (NIPORT) et al., Bangladesh Demographic and Health Survey 2007, Dhaka, Bangladesh: NIPORT and Mitra and Associates; and Calverton, MD, USA: Macro International, 2009

23. NIPORT et al., Bangladesh Demographic and Health Survey 2011, Dhaka, Bangladesh: NIPORT and Mitra and Associates; and Calverton, MD, USA: Macro International, 2012

\section{RESUMEN}

Contexto: La necesidad no satisfecha de anticoncepción se ha convertido en un concepto central en el campo de la planificación familiar y en uno de los indicadores más importantes para la planificación y la evaluación de los programas. Esta medida, sin embargo, ha enfrentado críticas por no tomar en cuenta la intención expresada por las mujeres de usar anticonceptivos.
Métodos: Este estudio utiliza datos longitudinales de más de 2,500 mujeres ubicadas en 128 poblados del medio rural en Bangladesh. El estudio vincula la adopción de anticonceptivos por parte de las mujeres y su experiencia de embarazos no deseados en el período 2006 a 2009, con su estatus respecto a las necesidades no satisfechas y su intención expresa de usar anticonceptivos en el año 2006.

Resultados: La intención de usar un método resultó ser un elemento predictivo de su posterior uso por mujeres con y sin una necesidad no satisfecha. Tres cuartas partes de los embarazos no planeados que se reportaron entre 2006 y 2009 se dieron en mujeres que no tenían una necesidad no satisfecha en 2006. Además, cerca de la mitad de las mujeres que no tenían una necesidad no satisfecha y que estaban embarazadas o en período postparto en 2006 habian experimentado un embarazo no deseado, comparado con el 30\% del total de mujeres clasificadas con una necesidad no satisfecha.

Conclusión: Para satisfacer de manera adecuada las necesidades de planificación familiar de la población, los programas tienen que mirar más allá de las necesidades no satisfechas y concentrarse en la demanda total de métodos aceptables y efectivos.

\section{RÉSUMÉ}

Contexte: Le besoin non satisfait de contraception est devenu un concept central de la planification familiale et l'un des principaux indicateurs sur le plan de la planification et de l'évaluation des programmes. Faute de considération de l'intention féminine déclarée de pratiquer la contraception, la mesure est cependant vulnérable à la critique.

Méthodes: En utilisant des données longitudinales relatives à plus de 2.500 habitantes de 128 villages du Bangladesh rural, cette étude lie l'adoption de la contraception et l'expérience d'une grossesse non désirée entre 2006 et 2009 à l'état de besoin non satisfait des femmes et à leur intention déclarée de pratiquer la contraception en 2006.

Résultats: L'intention de pratiquer une méthode est prédictive de pratique ultérieure pour les femmes présentant un besoin non satisfait ou non. Trois quarts des grossesses non planifiées déclarées entre 2006 et 2009 sont survenues parmi les femmes sans besoin non satisfait en 2006. De plus, près de la moitié des femmes sans besoin non satisfait qui étaient enceintes ou post-partum en 2006 avaient eu une grossesse non désirée, par rapport à 30\% de l'ensemble de celles classées comme présentant un besoin non satisfait.

Conclusion: Pour répondre adéquatement aux besoins de planification familiale de la population, les programmes doivent porter leur attention au-delà du besoin non satisfait et se concentrer sur la demande totale de méthodes acceptables et efficaces.

\section{Acknowledgments}

This research was supported by the National Institute of Child Health and Human Development (grant no. R01 HD042542-2). Associates for Community and Population Research was responsible for data collection.

Author contact: rcallahan@fhi360.org 